\title{
FRANCISCO DE CLEVES, UN PINTOR FLAMENCO EN LAS CORTES DUCALES DEL INFANTADO Y PASTRANA
}

\author{
POR \\ ROBERTO GONZÁLEZ RAMOS \\ Universidad de Córdoba
}

Este artículo aporta una visión de conjunto sobre la vida y actividades de uno de tantos pintores flamencos activos en España a caballo entre los siglos XVI y XVII: Francisco de Cleves. Un análisis detallado de las diferentes referencias sobre su figura que ha recogido la historiografía, y la profundización en las fuentes documentales, permiten aproximarnos bastante a las circunstancias vitales y profesionales de un artífice al servicio de dos de las casas nobiliarias más importantes de su tiempo, las ducales del Infantado y Pastrana.

Palabras clave: Francisco de Cleves/Frans van Cleve. Hendrick van Cleve III. Colecciones de pintura. Duque del Infantado. Duque de Pastrana. Pintura flamenca en España.

This study offers a complete vision of the life and activities of one of the many Flemish artists active in Spain between the late sixteenth and early seventeenth centuries: Francisco de Cleves. Detailed analysis of the historiographic references to him and thorough examination of the documentary sources permit an approximation to the personal and professional circumstances of an artist who served two of the most important ducal houses of his day: Infantado and Pastrana.

Key words: Francisco de Cleves/Frans van Cleve. Hendrick van Cleve III. Painting collections. Duke of the Infantado. Duke of Pastrana. Flemish painting in Spain.

Francisco de Cleves nació en Amberes. Era hijo de Hendrick van Cleef, o van Cleve, miembro de una amplia familia de pintores, y de Paschasia Suys 1 . Ambos contrajeron matrimonio en la iglesia de San Jacobo (Sint Jacobskerk) de la ciudad del Escalda el 2 de julio de $1555^{2}$. Tuvieron, según recoge la historiografía internacional, tres hijos: Gillis, Hans y Hendrik, también pintores. A esta nómina de vástagos debemos ahora sumar un cuarto, Frans.

1 Archivo Histórico de Protocolos de Pastrana. Escribano Andrés Escolar. Año 1611. Folio 464 ro. Testamento de Francisco de Cleves: "yn dey Nomine amen sepan quantos esta carta de Testamento Vieren como yo franco de cleves pintor $v z^{\circ}$ desta villa de pastrana natural que soy de la ciudad de anveres en el rreyno de vrabante Hijo de anrrique de 
Hendrik van Cleve III fue hijo del pintor Willem van Cleve el viejo. Nació en Amberes en 1525, siendo discípulo de su padre y de Frans Floris. Estuvo en Italia, donde pintó y recogió abundante material a base de dibujos para la realización de vistas de Roma y de otras ciudades transalpinas. Su especialidad era la del paisaje, que supo plasmar en lienzos y en dibujos, algunos de ellos grabados por Philips Galle, entre los que destacan vistas de la Roma moderna y de sus ruinas antiguas. Al parecer, pintó paisajes en obras de su hermano Willem y de Frans Floris. En 1551 fue admitido como maestro en el gremio de San Lucas de su ciudad natal. Su matrimonio con Paschasia Suys le granjeó una gran fortuna. Tuvo numerosas propiedades inmobiliarias que le proporcionaron buenas rentas y alto nivel de vida. Falleció en Amberes en 15903.

Pero centrémonos en el nombre que nos ocupa. Frans van Cleef, van Cleve, o Francisco de Cleves -castellanizando su nombre y apellido-, nació entre 1562 y 1573, como enseguida veremos. Debió tener su primer aprendizaje en su ciudad natal, seguramente en el taller de su propio padre. No tenemos más información al respecto y únicamente podemos constatar que su nombre nunca fue anotado en el libro del gremio de pintores de San Lucas de Amberes ${ }^{4}$. Se formaría en línea con los prototipos pictóricos de la ciudad del tercer cuarto del siglo XVI, dentro del particular romanismo flamenco tan repleto de temáticas mitológicas, paisajísticas y de género. Muy joven, y por razones que desconocemos, aparece en Castilla en 1587. Contaba con menos de veinticinco años, aunque era ya mayor de catorce. Se encontraba en Guadalajara, cosa que sabemos gracias al contrato que firmó para entrar al servicio, como pintor y criado, de D. Rodrigo de Mendoza, hermano y yerno del V duque del Infantado D. Íñigo López de Mendoza y Luna. Casado con la primogénita, doña Ana de Mendoza, D. Rodrigo era, por lo tanto, el heredero de la casa del Infantado 5 .

cleves pintor y de pasquala Sois mis padres[...]". Documento publicado parcial y libremente por García López, A.: "La comunidad flamenca en la España de los Austrias: La marginación de los pintores flamencos de Pastrana (Guadalajara)", Wad-Al-Hayara, 26, 1999, pp. 175-177. Este investigador señala, erróneamente, que Francisco de Cleves era un pintor desconocido hasta que él aportara ciertos datos -que veremos- sobre el pintor, además de éste.

2 Van Der Branden, F. J.: Geschiedenis der Antwerpsche Schilderschool, Amberes, 1883, p. 295.

3 Sobre Hendrik van Cleef, o van Cleve, III, la bibliografía es muy extensa. Citaremos aquí algunos títulos importantes: Van Mander, C.: Livre des Peintres. Vies des peintres flamands, hollandais et allemands, (ed. original, Haarlem, 1604) ed. Henri Hymans, París, 1884, tomo I, p. 272; Kramm, C.: De levens en werken der Hollandsche en Vlaamsche kunstschilders, Amsterdam, 1857, vol. I, p. 238; Van Der Branden, F. J.: Op. cit., pp. 184, 294 y 295; Wurzbach, A. von: Niederländisches Künstler-Lexikon, Viena-Leipzig, 1906, vol. I, p. 288; Thieme, U. y Becker, F.: Allgemeines Lexikon der bildenden künstler von der antike bis zur gegenwart, Leipzig, 1912, tomo VII, pp. 96-97; Hollstein, F. W. H.: Dutch and Flemish etchings, engravings and woodcuts ca. 1450-1700, Amsterdam, 1950, vol. IV, p. 170; Wilensky, R. H.: Flemish painters, 1430-1830, Londres, 1960, vol. I, pp. 526-527; Terlinden, CH.: "Une vue de Rome, par Hendrik van Cleve", Bulletin des Musées Royaux des Beaux-Arts de Belgique, IX, 1960, pp. 165-174; Blankert, A. y Van Hasselt, C.: Artisti olandesi e fiamminghi in Italia. Disegni del Cinque e Seicento della collezione Frits-Lugt, (cat. de la exp.) Florencia, 1966, p. 41; Van Der Meulen, M.: "Cardinal Cesi's Antique Sculture Garden: Notes on a Painting by Hendrick van Cleef III", The Burlington Magazine, CXVI, n. 850, 1974, pp. 14-24; Pieter Bruegel d. Ä. Als Zeichner. Hertkunft und Nachtfolge, Berlín, 1975, pp. 105-107; Orenstein, N. "The large Panorama of Rome by Hendrick Hondius I after Hendrick van Cleef III”, Bulletin van het Rijksmuseum, XXXVIII, 1990, pp. 25-36; VV.AA.: Fiamminghi a Roma. 15081608. Artistes des Pays-Bas et de la Principaute de Liege a Rome a la Renaissance, (cat. de la exp.) Bruselas-Roma, 1995, p. 136.

${ }^{4} \mathrm{Cfr}$. De liggeren en andere Historische archieven der antwerpsche Sint Lucasgilde onder zinsprenk "Wt lonsten versaemt”..., Amberes-La Haya, 1864-1876 (reimpresión Amsterdam, 1961), vol. I (años 1453-1615).

${ }^{5}$ Rodrigo de Mendoza era hermano segundo del V duque del Infantado. Gentilhombre de Cámara de Felipe II, adelantado de Cazorla y comendador de los Bastimentos de León de la Orden de Santiago, residía habitualmente en Madrid. En 1581 se encontraba en Portugal sirviendo al rey, pero acudió a la llamada de su hermano que, ante la falta de un heredero varón, había decidido casarlo con su hija. El enlace, previa dispensa por parentesco del Papa Gregorio XIII, se celebró en Guadalajara el 20 de enero de 1582. Véase Arteaga y Falguera, C.: La Casa del Infantado, cabeza de los Mendoza, Madrid, 1944, tomo II, pp. 7-19. 
Cleves firmó el aludido contrato el 10 de marzo de ese año ante el escribano público de la ciudad arriacense Diego de Cisneros ${ }^{6}$, que actuaba como notario de la casa ducal. Ya en el encabezamiento de dicho documento se dice que nuestro pintor era natural de Amberes, en el "Estado" de Flandes, estante y residente en la ciudad de Guadalajara. El contrato se firmó con validez por un período de dos años, en los cuales el joven pintor flamenco cobraría tres ducados al mes, gozando, además, del pago de su residencia ("posada"), médico, medicinas, un vestido al año "En la forma e Según q[ue] El dho $S^{o r}$ don Rodrigo Se lo quisiere dar", y una ración de comida diaria, compuesta de un pan, una libra de carnero y medio azumbre de vino. Debía ocuparse de servir a D. Rodrigo de Mendoza en su oficio de pintor y estar a su disposición para cualquier otro menester. Para desarrollar su profesión artística, el contratante debía proporcionarle "todas Las colores y aparejos que fueren neçesarios y aposento acomodado para pintar", incluyéndose el coste de moler los colores. De una forma poco clara, se incluye entre estas condiciones y prestaciones por su trabajo referidas, otra relativa a que "fuera desto se le a de dar El bestido de [...] que a servido al dho Sor don $R^{o}$ que no se le a dado y la Rata (sic) del dho salario y Raçión dende $q$ [ue] Sirbe pa lo q[ua]l tiene Reçebidos diez E ocho ducados e no otra cosa", lo que parece indicar que previamente al otorgamiento de este contrato, el pintor flamenco había estado al servicio de D. Rodrigo de Mendoza algún tiempo. Las alusiones al vestido que no se le había dado, a los 18 ducados y a la "rata" o porcentaje, parecen indicar que llevaba casi un año trabajando para él, a tenor de lo que se especifica en el contrato. Como no tenemos noticias de que D. Rodrigo hubiera estado en Amberes (o en Flandes), hemos de suponer que Cleves entablaría contacto con él y entraría a su servicio en Madrid o en la propia Guadalajara. Quizás el pintor había llegado a la Corte desde Amberes de mano de algún antiguo cargo de la administración española de los Países Bajos.

El documento que ligaba a Francisco de Cleves con D. Rodrigo aporta alguna otra información de interés. De entre lo habitual entre este tipo de escrituras encontramos referencias a la imposibilidad de ausentarse de Guadalajara (sin permiso, es de suponer) en los dos años estipulados. Más importante, y mucho menos habitual en las escrituras de este signo, es la referencia a que era menor de veinticinco años, aunque mayor de catorce, por lo que se le obligaba a un juramento extraordinario con el fin de dar mayor firmeza al documento ${ }^{7}$. Al final de la escritura hay una alusión de la que se desprende que Francisco de Cleves no estaba satisfecho con los testigos, entre los que se encontraba el también pintor flamenco Felipe Bosque ${ }^{8}$, por lo que este último hubo de jurar de forma extraordinaria. Esto puede indicar que no se fiaba de él o, quizás, que no lo conocía. Que no conociese a uno de los pintores flamencos de la Guadalajara de la época nos indicaría el poco tiempo que llevaba en la villa, pues es de suponer que una de las personas que primero entablarían contacto con él sería uno de sus compatriotas y, además, compañero de profesión.

${ }^{6}$ Archivo Histórico Nacional (AHN). Nobleza (Toledo). Osuna. Leg. 3398, $n^{\circ} 10$ (Letra J). Escribano Diego de Cisneros. Escrituras 1585-87. Folios $659 \mathrm{r}^{\mathrm{o}}$ y ss. Deteriorado en algunas partes, no puede leerse en toda su extensión, especialmente en ciertas zonas del margen derecho. Es por ello que, en ocasiones, señalamos el vacío producido con puntos suspensivos entre corchetes. Esto afecta al mes y al año del documento, pero se encuentra archivado en un registro de escrituras bien ordenado y, tanto los documentos que preceden, como los que van detrás de este, están fechados en marzo de 1587.

La existencia de este documento fue dada a conocer por Muñoz Jiménez, J. M.: "Arquitectura, Arte y poder en la Guadalajara del duque del Infantado a la luz de nuevos documentos (1560-1606)", Wad-Al-Hayara, 25, 1998, p. 404.

${ }^{7}$ En algún otro documento, como en este, podemos ver que cuando el contratado, fiador u otro era menor de edad, es decir, menor de veinticinco años, se le solía obligar a un juramento extraordinario para que no reclamase su minoría como causa de rescisión o invalidez del documento.

8 Sobre Felipe Bosque véase: Herrera Casado, A.: "Felipe Bosque y Gabriel Girandés, dos pintores flamencos en Hita", Wad-Al-Hayara, 7, 1980, pp. 287-289; véase también la referencia que aparece en Corella Suárez, P.: Arquitectura religiosa de los siglos XVII y XVIII en la provincia de Madrid. Estudio y documentación del Partido Judicial de Getafe, Madrid, 1979, p. 73. 
El mismo año 1587 nos ofrece otra noticia sobre Francisco de Cleves. Aparece como tasador de unas pinturas que había realizado el pintor complutense Juan de Cerecedo al servicio de la Universidad de Alcalá de Henares. Aquél pintor, que había fallecido recientemente, había realizado toda una serie de pinturas de contenidos emblemáticos, laudatorios y decorativos en 1579-80, con motivo de la frustrada visita del rey Felipe II y de su sobrino el archiduque-cardenal Alberto de Austria a la Universidad para que este último recibiese la imposición de un grado académico. Para el pago de dicho trabajo se había producido una primera tasación en 1580, que realizó Hernando de Ávila. La visita de los ilustres personajes no tuvo lugar finalmente -como indicábamos- y como parece que la Universidad realizó el encargo de la serie pictórico-decorativa sin autorización, se negó a pagar al pintor todo lo que le debía. Éste llevó a la institución académica ante el único tribunal que, por fuero, podía tratar su caso: el Real Consejo de Castilla. Pasados los años, el rey había fallado -hacia 1587- dictaminando que se realizase una segunda tasación, con peritos nombrados por cada una de las partes. Cerecedo falleció en 1587, por lo que se encargó de sus intereses su viuda, Martina de Herrera, quien nombró como su tasador a otro pintor de Alcalá, Manuel de Andrada 9 . La Universidad eligió para que defendiera sus intereses como perito a Francisco de Cleves, que recibió (firmando la correspondiente carta de pago) 66 reales por su labor tasadora el 9 de diciembre de $1587^{10}$. En la carta de pago y otros documentos contables de la Universidad de Alcalá, se señala que Cleves había sido nombrado por el Colegio Mayor de San Ildefonso y acudido desde Guadalajara, donde era "residente". Puede parecer sorprendente que un pintor joven, vecino de Guadalajara y, por lo que parece, prácticamente recién llegado a la ciudad alcarreña, fuese contratado por el Colegio Mayor complutense para una labor aparentemente tan delicada. Pero hemos de pensar que trabajaba para el yerno y hermano del duque del Infantado quien, como se sabe, era uno de los patronos de la Universidad de Alcalá. Por su mediación, seguramente, se consiguió recabar sus servicios. Además, sería preferible para los colegiales hacerse con los servicios de un pintor que ni fuese de Alcalá $-\mathrm{y}$, por lo tanto, conocido del fallecido y demandante- ni tuviese demasiados intereses profesionales en la zona, para asegurar su imparcialidad.

El contrato que Cleves había firmado por dos años de servicio no llegó a cumplirse en su totalidad. D. Rodrigo de Mendoza falleció en Guadalajara el 2 de octubre de 158811. Veremos abajo lo que esto pudo suponer en relación con nuestro Francisco. De momento, no podemos dejar de aludir a otra curiosa noticia que nos aporta datos sobre el pintor flamenco. La almoneda de D. Rodrigo se realizó a partir del 20 de noviembre del mismo año, alargándose en días sucesivos. Pues bien, en numerosas partidas de compras de lotes de bienes del difunto, aparece un tal "Francisco pintor", que era, con la mayor de las posibilidades, el propio Cleves que había estado al servicio del difunto ${ }^{12}$. Francisco de Cleves compró de entre los bienes de la almoneda de su señor, una jerguilla verde forrada en tafetán pardo con un pasamano de plata, que le costó 13 reales $^{13}$; dos pares de zapatos de cordobán blanco, por 10 reales; un sobrero de tafetán negro y algunos adornos de oro y plata, por 40 reales ${ }^{14}$; una "ropilla", una capa corta forrada y unas calzas conjuntadas de jerguilla azul y adornos de seda, junto con una montera y un jubón, por 50 ducados

\footnotetext{
${ }^{9}$ González Ramos, R.: "La visita del archiduque cardenal Alberto de Austria a la Universidad de Alcalá de Henares y la obra efímero-emblemática del pintor Juan de Cerecedo", Boletín del Museo e Instituto "Camón Aznar", XC, 2003, pp. 77-98.

${ }^{10}$ AHN. Universidades: Leg. 138 (4). Sin foliar, $\mathrm{r}^{\mathrm{o}}$. y v ; Libro 196. Folio $206 \mathrm{v}^{\mathrm{o}}$; Libro 849. Folio $155 \mathrm{r}^{\mathrm{o}}$.

${ }^{11}$ Fecha que aparece en el propio inventario post mortem del finado y en otro documento, que citamos más abajo, donde se recogen las deudas que dejó: AHN. Nobleza (Toledo): Osuna. Leg. 1836, nº. 1,1-2; Osuna. Leg. 3398, nº 12 (Letra L).

12 AHN. Nobleza (Toledo). Osuna. Leg. 3398, n 11 (Letra K). Escribano Diego de Cisneros. Escrituras 1588-89. Folio $286 \mathrm{r}^{\mathrm{o}}$ y ss.

13 Ibid. Folio $287 \mathrm{r}^{\circ}$

14 Ibid. Folio $288 \mathrm{r}^{\circ}$.
} 
"en reales"15; un ceñidor de tafetán, por 13 reales; unos zapatos de baqueta, otros de cordobán blancos y dos pares más de zapatos viejos, por 14 reales ${ }^{16}$; unas botas de cordobán nuevas, por 12 reales ${ }^{17}$; dos pares de botas blancas, por 20 reales ${ }^{18}$; dos pares de medias calzas de punto de seda, por 10 ducados "en reales"19; unos zapatos blancos pintados forrados en tafetán blanco, por 8 reales ${ }^{20}$; dos pares de calcetas de Holanda, seis pares de escarpines y otras piezas de vestir, por 33 reales ${ }^{21}$.

Todo ello nos indica que el pintor tenía una posición económica relativamente buena. Tal cantidad de piezas de ropa y calzado podía ser para él, lo que nos hablaría de cierto porte aristocrático, o para después revenderse, lo que indicaría ciertos usos mercantiles a presuponer en la forma de ser de un pintor flamenco. Es de destacar que no aparecen en la almoneda partidas significativas relativas a cuadros de pintura, salvo alguna interesante como la que se refiere a una serie de doce emperadores. Aparecen como compradores, entre otras muchas personas, tanto el duque como su hija y viuda del difunto -la que más compras hizo-. En el inventario de bienes post mortem de D. Rodrigo encontramos algunas "imágenes", la mayoría de tipo religioso -excepto los aludidos doce cuadros de emperadores-. No podemos saber si alguna de ellas fue realizada por Cleves mientras le sirvió 22 .

En 1591 se redactó un memorial en el que se declaran las deudas que había dejado D. Rodrigo tras su deceso. Como no podía ser menos, aparece entre la amplia relación de acreedores nuestro Francisco de Cleves. Según el documento, se le debía la cantidad de 47.124 maravedíes "de su partido y vestidos q[ue] se le deven tasados a veinte y çinco Ducados cada uno"23.

Como decíamos arriba, el fallecimiento de su patrón dejaría a nuestro pintor, en principio, sin más medio de vida que el del oficio artesano de la pintura, como un profesional más, abocado a competir en un mercado bastante copado. Y, desde luego, sin la protección de un noble que lo tuviese contratado a manera de "pintor de corte". Sin embargo, sabemos por fuentes documentales que Cleves pasó de servir al yerno y heredero del V duque del Infantado, a trabajar para este mismo.

Hace ya bastante tiempo que tenemos noticias de que Francisco de Cleves había sido algo parecido a un pintor "oficial" del V duque del Infantado 24 . Así lo demuestra que en el inventario de los bienes de este destacado noble, redactado tras su muerte en 1601, aparezcan bastantes obras que se declara fueron realizadas por el pintor flamenco ${ }^{25}$.

15 Ibid. Folio $289 \mathrm{v}^{\circ}$.

16 Ibid. Folio $291 \mathrm{r}^{\circ}$.

17 Ibid. Folio $291 \mathrm{v}^{\circ}$.

18 Ibid. Folio $298 \mathrm{v}^{\mathrm{o}}$.

19 Ibid. Folio $302 \mathrm{v}^{\mathrm{o}}$.

20 Ibid. Folio $317 \mathrm{r}^{\circ}$.

21 Ibid. Folio $350 \mathrm{v}^{\mathrm{o}}$.

22 AHN. Nobleza (Toledo). Osuna. Leg. 1836, $n^{\circ}$ 1, 1-2. Encontramos, al principio, ciertas imágenes pequeñas en tabla. Más adelante (folio $118 \mathrm{v}^{\circ}$ ) otra serie más extensa de imágenes: San Cristóbal, Ecce Homo, La Virgen, el rostro del Salvador -pequeña-, San Francisco con un Cristo, El Salvador con un fariseo con una moneda en la mano -grande-, San Francisco y Santo Domingo -pequeña-, San Cristóbal -pequeña-, una Nuestra Señora "de la Huída a Egipto" y doce cuadros "retratos" de Emperadores.

23 A.H.N. Nobleza (Toledo). Osuna. Leg. 3398, nº 12 (Letra L). Escribano Diego de Cisneros. Escrituras 1590-91. Folio $924 \mathrm{v}^{\circ}$. Algunos de los acreedores eran habitantes de Madrid, villa en la que había residido largo tiempo el finado. Entre ellos "xácome de trenço escultor $V^{o}$ de $m^{d ",}$, al que se le debían pagar 500 reales "de obras $q$ hizo de su of".

${ }^{24}$ Morán, M. y Checa, F.: El coleccionismo en España. De la cámara de maravillas a la galería de pinturas, Madrid, 1985, p. 169. También Muñoz Jiménez, J. M.: "Las colecciones de pintura del Palacio del Infantado de Guadalajara en la segunda mitad del siglo XVII", Actas del VII Congreso Español de Historia del Arte, Murcia, 1992, p. 326.

25 AHN. Nobleza (Toledo). Osuna. Leg. 1948, $n^{\circ}$. 3. Folio $1 \mathrm{r}^{\circ}$ y ss. Es de señalar, como hicieran en su día los citados Morán y Checa (ob. cit., p. 169), que la colección del V duque del Infantado destaca por la mayoritaria presencia de 
Resulta poco común, a la par que feliz para el conocimiento del pintor que nos ocupa, que en un inventario de bienes se anotasen las atribuciones de diversas obras a un artífice que no fuese declaradamente famoso o de primerísima fila, al menos en estas fechas. Pero en el citado inventario aparecen muchas obras asignadas a Cleves sin ninguna duda. Las primeras obras inventariadas de entre las que el V duque del Infantado coleccionó a lo largo de su vida que afectan a la producción de Cleves, aparecen acompañadas de la referencia de que eran "de mano de Francisco el pintor", lo que podría plantear alguna reserva. Pero más adelante aparecen, sin solución de continuidad, asignadas a "Francisco de Cleves, pintor", lo que aleja toda suspicacia ${ }^{26}$.

Las obras que nos afectan vienen descritas de la siguiente manera: cuatro lienzos, el primero de la historia de "Auton" -seguramente Acteón-, el siguiente "de unos tudescos salteadores entre árboles y riscos", otro de Argos y Mercurio, y un último de "unos lexos de arboledas y edificios antiguos con personajes a caballo", todos con marcos dorados. Otra partida señala la existencia de un lienzo grande "que hiço El dho frco El pintor del ssor. don rrodrigo de mendoça en que está pintada El arca de noé"27. El texto de la partida alude seguramente a un lienzo que llegó a pintar para D. Rodrigo y que representaba el Arca de Noé, aunque dicha obra no consta entre las pertenencias de dicho personaje en su inventario post mortem. Después, se anotaron en el registro otros dos lienzos "largos y angostos", es decir, apaisados, que se encontraban sobre las puertas de las alcobillas de la sala de D. Zuria del Palacio del Infantado, "que son unos lexos". Encontramos después dos lienzos grandes, uno de "Pocris y Céfalo" -Procris y Céfalo- y otro de Venus y Adonis, especificándose "que se conpraron del dho Francisco pintor"28. Más adelante encontramos un lienzo grande de "una Lucrecia". El siguiente era un lienzo grande de "urda (sic) ques una muger desnuda con un Çisne Ençima della quella le esta vesando", es decir, Leda y el Cisne, con marco negro y dorado. Más abajo tenemos otro lienzo grande con marco dorado y negro de "la diossa venus y cupido desnuda y sentada y El cupido La abraça" 29 . Tenemos después un lienzo grande de Diana y Acteón "que tiene En él pintadas ocho figurass Desnudas y la figura de anteón (sic) con sus Cuernos y tres perros Junto a Él y una fuente En medio y Ençima de la dha fuente un çiervo, que tiene de largo como tres baras y de ancho más de quatro baras" 30 . Otra obra era otro lienzo grande de "los tres apóstoles san pedro y santiago y san andrés quando andavan en el mar pescando con muchos xéneros de pescados", del que se especifica: "El qual dho lienço trasladó de otro como Él El dho franco Cleues pintor y tiene su marco"31. Después tenemos un lienzo que representaba "El rretrato de la casa del bosque de la villa de buytrago", es decir, que contenía la representación de una de las propiedades del duque del Infantado. Concretamente la villa "a la ita-

pintura flamenca (de hecho, abre la sección dedicada a pintura con un elocuente "lienços de flandes y otras pinturas"), lo que indica una preferencia clara, a lo que no es ajeno que Cleves fuese el pintor "oficial" de la Casa. Sin embargo, fue un italiano, Romolo Cincinato, el artífice de la decoración mural del Palacio del Infantado, encargada por el mismo patrono. Vid. Herrera Casado, A.: "El arte del humanismo mendocino en la Guadalajara del Siglo XVI", Wad-Al-Hayara, 8 , 1981, pp. 345-384; Marías, F.: "Los frescos del palacio del Infantado en Guadalajara: problemas históricos e iconográficos", Academia. Boletín de la Real Academia de Bellas Artes de San Fernando, 55, 1982, pp. 175-216.

El programa histórico-genealógico y mitológico de la decoración parietal del palacio, bien pudiera haberse visto complementado por las obras de Cleves, aunque un tanto tardíamente y con unas referencias estilísticas seguramente diversas.

26 A.H.N. Nobleza (Toledo). Osuna. Leg. 1948, $n^{\circ}$. 3. Folio $51 \mathrm{r}^{\circ}$ y ss. Este inventario aparece transcrito -con algunos fallos- en Burke, M. B. y Cherry, P.: Collections of Paintings in Madrid 1601-1755, Los Ángeles, 1997, I, pp.199203.

27 A.H.N. Nobleza (Toledo). Osuna. Leg. 1948, $\mathrm{n}^{\circ}$. 3. Folio $51 \mathrm{r}^{\circ}$.

28 Ibid. Folio $52 \mathrm{r}^{\circ}$.

29 Ibid. Folio $53 \mathrm{r}^{\circ}$.

30 Ibid. Folio $53 \mathrm{v}^{\circ}$.

31 Ibid. Folio $54 \mathrm{r}^{\circ}$. 
liana" que el noble había mandado edificar en esa localidad de su propiedad entre 1596 y $1601^{32}$. También encontramos registrado "otro lienço grande como rretablo del sepulcro de nro señor Jesuxpto que hiço El dho franco de cleues pintor para el oratorio de la cassa de la uilla de buytrago con su quadro grande de madera" 33 . Se trataba, qué duda cabe, de un gran lienzo realizado para decorar la capilla de la citada residencia. Por último se registran otros dos lienzos. Extrañamente, uno, se dice, representaba el Sepulcro y se hizo para Buitrago -quizás se registró por segunda vez la obra vista arriba-, y el otro era un bodegón, sin más especificaciones ${ }^{34}$.

Podemos comprobar que la producción de Francisco de Cleves para el duque del Infantado en Guadalajara fue bastante amplia, lo que sería suficiente como para afirmar que, en efecto, actuó como su pintor oficial o "de corte". Y es muy posible que trabajara a su servicio no sólo para decorar su palacio de Guadalajara o su villa campestre de Buitrago, sino también en otras ocasiones y con otros destinos. Durante largo tiempo, quizás desde poco después de la muerte de D. Rodrigo de Mendoza en 1588, y hasta 1601, Cleves debió ser criado del duque, miembro de su casa, además de su pintor.

Si intentamos seguir el rastro de alguna de las obras que aparecen en el inventario de D. Íñigo López de Mendoza al que nos hemos referido, podemos acudir a varios documentos. El más temprano fue realizado en Buitrago de Lozoya en 1620. Se redactó con motivo de la entrega de bienes del guarda mayor de la aludida "casa del bosque" de esa localidad ${ }^{35}$. Entre los bienes que se hallaban en ella encontramos un cuadro en el oratorio, que representaba el Descendimiento. Quizás se asimile este tema con el del Sepulcro de Jesucristo (su sepultura) que se cita dos veces en el inventario del $\mathrm{V}$ duque del Infantado como obra de Cleves y destinada a este ámbito, aunque resulta bastante extraño. Sin embargo, es tan extraño como que en el breve lapso de diecinueve años se hubiese cambiado el gran cuadro de altar del oratorio de dicha casa por otro nuevo, sin motivo aparente. Podrá permitírsenos que pensemos en confusiones de los escribanos o en la escasa claridad de la obra en cuestión más que en un supuesto cambio de "retablo". También cabe la posibilidad que el cuadro que pintó Cleves y que se inventarió en Guadalajara, nunca llegara a trasladarse a la casa de Buitrago.

Más importante e interesante es el inventario realizado en Madrid el 3 de agosto de 1624 con motivo del fallecimiento del VI duque del Infantado, D. Juan Hurtado de Mendoza, hijo del Marqués de Mondéjar, casado con doña Ana de Mendoza de la Vega y Luna, duquesa del Infantado, viuda del aludido D. Rodrigo, hija y heredera del V duque D. Íñigo ${ }^{36}$. En este documento encontramos una amplísima colección de pinturas -todas ellas en su residencia en la Corte-, lógicamente sin que se señalen autorías, la mayoría coleccionadas por el propio fallecido. Pero un buen número de ellas le pertenecía en tanto que herencia de su antecesor y suegro, como se especifica claramente en las distintas partidas que, machaconamente, indican que tal o cual obra "hera del dho sr duque don yñigo que se halló Entre los demás Vienes que dexó". Algunas de esas pinturas, especialmente por cuestiones de coincidencia temática, se declaran claramente como las que Francisco de Cleves había realizado mientras sirvió al V duque ${ }^{37}$.

32 La Casa del Bosque de Buitrago, villa a la "palladiana”, como la denominó José Miguel Muñoz Jiménez, fue iniciada en noviembre de 1596 y construida bajo la dirección del maestro de obras del duque, Diego de Valera. Al parecer, fue concluida en 1601. Sobre la obra y su documentación relativa, véase, especialmente: Muñoz Jiménez, J. M.: "La Casa del Bosque de Buitrago (Madrid) y la villa rústica en España”, Villa de Madrid, XXIX, nº 107, 1992, pp. $37-58$.

33 AHN. Nobleza (Toledo). Osuna. Leg. 1948, $n^{\circ}$. 3. Folio $55 \mathrm{v}^{\circ}$.

34 Ibid. Folio 83 ro.

35 AHN. Nobleza (Toledo). Osuna. Leg. 1664, $\mathrm{n}^{\circ} 2$. Sin foliar.

36 AHN. Nobleza (Toledo). Osuna. Leg. 653-5. Folio $2 \mathrm{r}^{\circ}$ y ss. Véase también la transcripción del documento del Archivo Histórico de Protocolos de Madrid realizada por Burke, M. B. y Cherry, P.: Op. cit., I, pp. 229-257.

${ }^{37} \mathrm{El}$ resto, en su gran mayoría, corresponden a las demás pinturas que aparecen en el inventario del duque D. Íñigo de 1601. Serían trasladadas desde el Palacio del Infantado a la residencia cortesana de los duques por el duque D. Juan. 
De esta forma, encontramos un lienzo grande que representaba "el arca de noé con mucho ganado y gran género de animales", que tenía marco dorado y que seguramente era el que, según el inventario de 1601, había hecho el flamenco para D. Rodrigo de Mendoza. Otro lienzo grande con marco dorado tenía "pintado en él san Pedro Santiago y San andrés con mucha pesca" y, más abajo, otro lienzo también grande, con marco dorado, presentaba "pintado en él san Pedro san andrés y Santiago pescando con gran cantidad de pescados". Evidentemente uno era el original que perteneció a D. Íñigo -que no aparece en el inventario de 1601- y el otro la copia que realizó Cleves de esa obra. También podemos localizar un lienzo grande con marco dorado "pintados en él Unos boscaxes y Unos ladrones escondidos En el bosque con Un árbol muy grande" que seguramente era el lienzo que aparecía en el inventario del V duque representando a unos "tudescos salteadores" entre árboles y riscos. Más abajo tenemos otra pintura sobre lienzo, con su marco dorado, que representaba a "céfano y coples Hechada en Unas bienes (sic) Con una saeta atravessada y una aljava de terçiopelo azul". Junto a esta obra tenemos otra, también con marco dorado, de temática similar, representando a "Zéfano y coples Sentada haziendo ayre a çéfano que está hechada en sus faldas Cupido en pie // Abrazado un perro y Unos paísses". Ya vimos que Cleves había realizado un lienzo de Céfalo y Procris al servicio del V duque, una iconografía poco usual y que Cleves volvería a tratar en años posteriores al fallecimiento de su señor. No podemos concretar si uno o ambos lienzos fueron pintados por Cleves.

Desgraciadamente, el siguiente duque del Infantado (VII) no conservó del grueso de la colección familiar -la madrileña-, más que los retratos de antepasados y alguna que otra obra aislada. Sin entrar aquí, puesto que no corresponde, en las razones que le llevaron a ello, podemos comprender que esto nos dejó sin la posibilidad de seguir con garantías el resto de las pinturas -sobre todo las debidas a Cleves- y, así, disponer de información precisa sobre sus características ${ }^{38}$.

Algunas otras obras, incluidas varias de las realizadas por Cleves y que se habían registrado en el Palacio del Infantado, debían seguir en su lugar. No todas se trasladarían a Madrid -veremos que algunas ya no constan documentalmente-. Lamentablemente, sólo hemos localizado algunos -pocosinventarios de bienes de dicho palacio realizados con posterioridad a 1601, y son bastante tardíos. Uno fue realizado en 1679, con motivo de la entrega de bienes a su alcaide ${ }^{39}$. En este documento aparecen bastantes obras de pintura, pero sólo algunas de ellas parecen corresponder a las que había ejecutado en su día Francisco de Cleves, varias situadas, además, en los mismos lugares.

En la planta baja del palacio, en una estancia grande situada bajo el llamado salón de los linajes, se encontraba un "quadro Sin marco de una fábula de Una mujer desnuda con su niño Con

Éste dejó de habitar el palacio de Guadalajara, trasladando su residencia a Madrid, desde 1604, cuando encargaba a uno de sus criados el cuidado del edificio y de los bienes que albergaba. Cfr. Herrera Casado, A.: Art. cit., 1981, p. 383.

Es de señalar que en la almoneda de D. Íñigo López de Mendoza y Luna, celebrada en 1603, encontramos numerosas ventas de pinturas. Además de ciertas imágenes religiosas, aparecen muchos lienzos de Flandes pintados al temple. Estos corresponden a un amplio grupo de cuadros de esa procedencia y técnica que aparecen en la primera partida del inventario de 1601: "çiento y tres lienços de pintura de diverssas ystorias con sus quadros y listas de molduras doradas que truxeron de flandes pintados al temple". Ninguna de las obras vendidas parece ser de las que se asignaban a Cleves. La almoneda puede consultarse en: AHN. Nobleza (Toledo). Osuna. Leg. 3398, $\mathrm{n}^{\circ}$ (Letra R). Escribano Diego de Cisneros. Escrituras 1604-05. Folio $111 \mathrm{r}^{\circ}$

38 Sobre la venta de la colección de pinturas de la casa del Infantado, con motivo de la partida del VII duque a su embajada en Roma en 1649, véase Arteaga y Falguera, C. de.: Op. cit., tomo II, pp. 72 y 521-23; Muñoz Jiménez, J. M.: Art. cit., 1992, p. 326.

En 1657 se hizo inventario de los bienes de D. Rodrigo de Mendoza, VII duque del Infantado, en Madrid. Poseía mayoritariamente obras italianas. Su inventario no menciona, salvo Ribera y Velázquez, ningún nombre que no fuese de esa nacionalidad. Véase: Archivo Histórico de Protocolos de Madrid (AHPM). Escribano Nicolás Martínez Serrano. Prot. 8226. Folio 12 r $^{\circ}$ y ss. Documento citado por Morán, M. y Checa, F.: Op. cit., p. 289.

39 AHN. Nobleza (Toledo). Osuna. Leg. 1878, $\mathrm{n}^{\circ} .2$, 13. Inventario de bienes del Palacio del Infantado del 2 de enero de 1679. Entrega al alcaide Jerónimo de Contreras Palomeque, presbítero. 
alas abrazándole". Este cuadro parece corresponder a la Venus con Cupido en acción de abrazarla inventariado en 1601. En la llamada sala de D. Zuria se conservaban "Dos payses largos de ençima de las alcobas desta sala", entre otras pinturas. Al menos los paisajes que se encontraban sobre las alcobas de la sala ya aparecían, como obra de Francisco de Cleves, en 1601, con el mismo formato y en el mismo lugar. No tenemos pruebas concluyentes que nos permitan relacionar otras obras con nuestro pintor.

Otros inventarios del Palacio del Infantado se realizaron en $1708^{40}$ y en $1714^{41}$, siempre con motivo de la entrega de bienes a su alcaide. En ambos volvemos a encontrar los tres lienzos citados, entre otros muchos. Añaden a lo que indica el registro de arriba que el cuadro que identificamos como el de Venus y Cupido obra de Cleves medía "bara y quarta de largo y una de ancho"42. También añaden información en cuanto a los dos paisajes sobre las puertas de las alcobas de la sala de D. Zuria. Medían "dos baras y $m^{a}$ : de largo y tres quartas de ancho". En los inventarios del palacio que hemos consultado correspondientes al siglo XIX no encontramos ninguna pintura de tema mitológico ni ningún paisaje que se ajuste a las medidas de los que se encontraban cerca de las alcobas de la sala de D. Zuria ${ }^{43}$. Sobre el resto de las pinturas que Cleves realizó para el V duque del Infantado no podemos aportar información adicional.

En el inventario realizado con motivo del deceso del V duque del Infantado, de 1601, encontramos, además de las pinturas vistas y otras muchas de autoría desconocida o conocida, un buen número de retratos. Algunos de ellos son de miembros de la Casa del Infantado, como es lógico, dos de ellos mostrando al propio duque recién fallecido. Uno de estos retratos, aún conservado (156 x $130 \mathrm{~cm}$.), mostrando a un D. Íñigo canoso y de una edad bastante avanzada, con toisón de oro al cuello (fig. 1.), se fecha alrededor de 1595 y suele incluirse dentro de la producción de algún seguidor de Alonso Sánchez Coello ${ }^{44}$. Esto es debido a que sus características estilísticas son tan fieles al modelo flamenco de retrato de aparato, que no cabe duda de que algún seguidor del pintor de Felipe II, adiestrado de lleno en la tradición de Antonio Moro, lo debería haber realizado, ya que no debe ser del mismo Sánchez Coello. Si pensamos que Cleves era pintor "de corte" del duque y que él mismo era un pintor flamenco, plenamente en activo para su patrono por los años en que se debió realizar el retrato, quizás fuese el autor de la obra. No debemos, por otra parte, poner como reparo a esta propuesta de atribución el hecho de que no conste en el citado inventario como obra de Cleves -ni de ningún otro-, al contrario que sus otras obras de diversos temas,

40 AHN. Nobleza (Toledo). Osuna. Leg. 1878, nº. 2, 14. Comentado por Muñoz Jiménez, J. M.: Art. cit., 1992, p. 330. Publicado en Codoin, LXXIX. Inventario general de entrega al alcaide del Palacio del Infantado, Francisco Bellosillo, 1708.

41 AHN. Nobleza (Toledo). Osuna. Leg. 1878, $n^{\circ} .2$, 20. Inventario de bienes del Palacio del Infantado del 30 de enero de 1714 (copia certificada del 24 de febrero). Entrega al alcaide Francisco Parrales.

42 AHN. Nobleza (Toledo). Osuna. Leg. 1878, $n^{\circ} 2,14$. Folio $2 \mathrm{r}^{\circ}$ y ss.

43 Esos inventarios, que aluden a las distintas salas y dependencias de forma bastante diferente a la de los documentos antes citados, sin que sea posible adivinar cuál estancia correspondía a cuál, son bastante completos. Había, al menos, un "Un país de dos varas de ancho, y cinco quartas de alto apaisado", junto a numerosos retratos y lienzos antiguos sin describir. Con esos inventarios perdemos definitivamente la pista de las posibles obras de Cleves. Inventarios de 1821 y de 1838 (AHN. Nobleza (Toledo). Osuna. Leg. 4328. N 2. Sin foliar).

44 VV.AA.: Alonso Sánchez Coello y el retrato en la corte de Felipe II, (cat. de la exp.) Madrid, Museo del Prado, 1990, p. 153. La obra se conserva en la Casa ducal del Infantado y aparece reproducida en la obra de Arteaga y Falguera, C. de.: Op. cit., tomo I, p. 376, lámina LVI. Se cita en Sentenach y Cabañas, D.: Catálogo de los cuadros, esculturas, grabados y otros objetos artísticos de la antigua casa ducal de Osuna..., segunda edición, Madrid, Viuda e hijos de M. Tello, 1896, p. 47, no . 151, como "Retrato de D. Íñigo López de Mendoza, de edad más avanzada [antes se cita otro, joven], quinto Duque del Infantado: ciñe lujosa armadura y lleva al cuello el Toisón de oro.- Figura hasta las rodillas; fondo obscuro". No hay que olvidar que la casa del Infantado acabó uniéndose a la de Osuna. Cfr. Atienza Hernández, I.: Aristocracia, poder y riqueza en la España moderna. La Casa de Osuna. Siglos XV-XIX, Madrid, 1987.

D. Íñigo López de Mendoza y Luna recibió el Toisón de Oro en 1593, por lo que quizás el retrato sea de ese año. 
Fig. 1. F. de Cleves (?): D. Íñigo López de Mendoza,

col. particular.

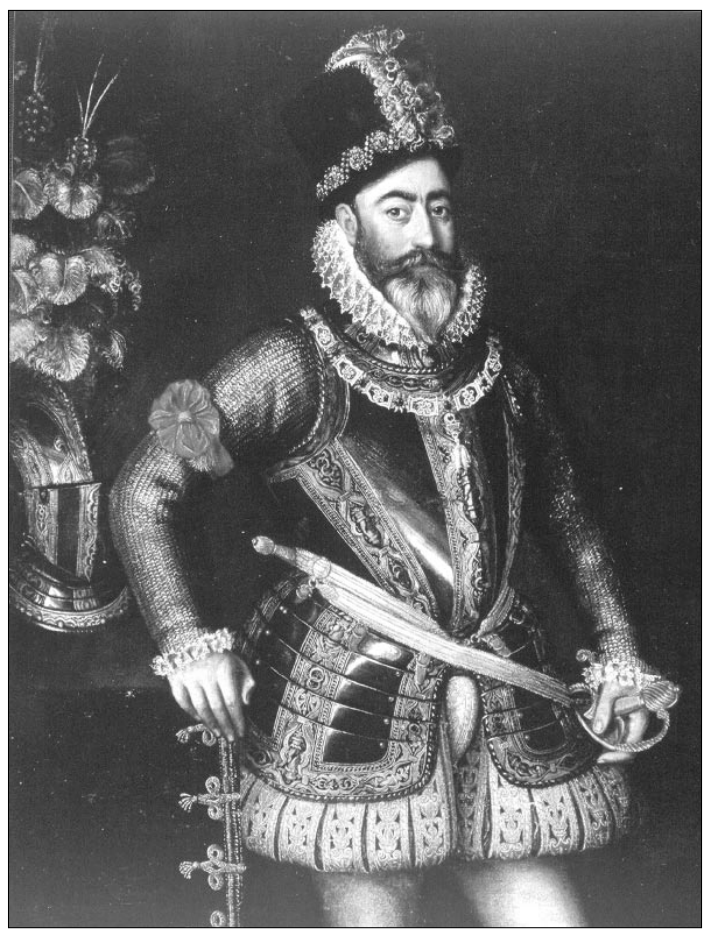

porque lo normal en el caso de retratos de personas conocidas -al igual que con las "personas reales" en los inventarios reales-, es que no se valoren ni se les dé más descripción que el nombre del efigiado y algún detalle. Debemos matizar que, salvo por el hecho de que en estas fechas Cleves estaba al servicio del duque, ningún otro dato concreto sostiene esta propuesta hipotética.

\section{Pastrana}

Con el fallecimiento del V duque del Infantado, otra vez Francisco de Cleves se quedaba sin protector $\mathrm{y}$, aunque pudiera haber trabajado para otras personas o instituciones e, incluso -no nos quepa duda-, tener taller propio y vender obras en el comercio -de las que, de momento, nada sabemos-, debió quedar en una situación bastante peor que la que había tenido. Ante esta situación, Francisco de Cleves no se quedó inactivo. Buscó alternativas que volvieran a situarlo en un lugar de privilegio en comparación con otros pintores menos "atractivos". No tuvo que ir muy lejos para lograrlo, pues ya en 1606 se encontraba al servicio de otro noble destacado: el duque de Pastrana, por aquellos años D. Ruy Gómez de Silva, tercero del título ${ }^{45}$. El año siguiente

45 El III duque de Pastrana nació en España, pero fue criado en Flandes. Hijo de los príncipes de Mélito, D. Rodrigo de Silva y Doña Ana de Portugal y Borja. Protegido de Felipe III. Gentilhombre de Cámara, Cazador Mayor, de los Consejos de Estado y Guerra, diplomático de habilidad en Italia. Murió en Madrid el 23 de diciembre de 1626. Véase Salazar y Castro, L.: Historia genealógica de la Casa de Silva, Madrid, 1685, II, p. 578, passim; Pérez, L.: "Los duques de Pastrana", Archivo Iberoamericano, 1922, pp. 48-69; entre otras fuentes y publicaciones. Aludía al trabajo de Cleves como criado del duque entre 1606 y 1611, García López, A.: Art. cit., p. 171. 
(1607), el mayordomo del duque anotaba en su libro de cuentas de la mayordomía de Pastrana el pago al pintor Francisco de Cleves de 15 fanegas y 10 celemines de trigo en concepto de la "Raçión de q[ue] el duq[ue] mi s ${ }^{r}$ Le haçe merced como constó de una carta de su $S^{a}$ escripta al $d^{r}$ Antonio fortea pres ${ }^{\text {te }}$ del conss ${ }^{o}$ de Su $S^{a}$ : desde Primero de abril del año Passdo de Seisçi ${ }^{o}$ y $y$ seis hasta fin de Agosto de 1607 a rrazón de Sesta y quatro mrs Cada día y en pan"46. Nuestro flamenco había entrado al servicio del duque de Pastrana que, desde fecha indeterminada (parece que desde el 1 de abril de 1606), le ofrecía una ración o sueldo. Tenemos constancia documental de que dicha ración se le siguió abonando hasta 1609. En 1608 se anotaba en el referido libro de cuentas del mayordomo del duque el pago de 27.200 maravedíes en concepto de la ración cobrada entre el 1 de enero de 1607 y el último día de febrero de $1608^{47}$. Entre el 1 de marzo de 1608 y final de mayo de 1609 recibió un pago de 5.800 maravedíes por el mismo concepto, a razón de 64 maravedíes diarios ${ }^{48}$. Desde el 1 de mayo de 1609 aún se le vinieron abonando maravedíes por la ración, pero con indicación de que el duque había dejado de otorgársela desde el 4 de septiembre $^{49}$. Ignoramos las causas de tal cese. El último pago recogido sumó 5.660 maravedíes.

Aunque no contamos con una relación tan extensa y elocuente como la del inventario de bienes del V duque del Infantado sobre las obras realizadas por Cleves para su nuevo patrono ${ }^{50}$, tenemos varias noticias de ciertas obras que realizó para el duque de Pastrana. En el inventario post mortem del noble, de 1626, una partida registra la existencia en su colección de "Quatro quadros grandes de Hermitaños del yermo que pintó cleues sin marcos" 51 , obras a las que nos referiremos más adelante. El inventario no presenta más noticias que nos afecten, aparentemente.

Otra noticia, más curiosa e interesante, se refiere a un lienzo que Cleves pintó en 1607. Diversos datos, procedentes del mismo libro de mayordomía de Pastrana que hemos visto arriba sobre los salarios del pintor al servicio del noble, señalan que ese año ejecutó un cuadro que representaba una "Cena", es decir, una Última Cena de Jesús con los Apóstoles. La partida contable relata que a Francisco de Cleves, pintor, se le abonó la cantidad de 300 reales por "toda la costa y trauajo que puso en el Lienço de la Zena que hiço para el Duq ${ }^{e}$ mi $S^{r, 52}$. Dicha obra, según otra partida, fue "acomodada", antes de ser enviada a Sanlúcar de Barrameda (Cádiz) por el duque de Pastrana: " $q[\mathrm{ue}]$ el Duq mi $S^{r}$ embió a S. Lúcar Como de una memoria de miguel de Uçeda cons$t a " 53$. Cierta cantidad se pagó a un carpintero "por un bastidor que hizo en la ventana donde Cleves pintó el lienzo de la Cena" 54 .

Las relaciones entre las casas de Pastrana y Medina Sidonia (Con solar en Sanlúcar) fueron fluidas en esta época. Una hija de los primeros duques, los famosos Ruy Gómez de Silva y de Ana de Mendoza, príncipes de Éboli, había contraído matrimonio en 1572 con D. Alfonso Pérez de Guzmán, duque de Medina Sidonia. El tercer duque de Pastrana casó con doña Leonor de Guzmán, su prima e hija del citado, en 1601 en Sanlúcar de Barrameda. Se sabe que en septiembre de

\footnotetext{
46 AHN. Nobleza (Toledo). Osuna. Leg. 3404, nº 3. Libro de mayordomía de Pastrana. Cuentas 1606-1626. Folio $710 \mathrm{v}^{\circ}$.

47 Ibid. Folio $776 \mathrm{v}^{\circ}$

48 Ibid. Folio $845 \mathrm{r}^{\circ}$.

49 Ibid. Folio $896 \mathrm{v}^{\circ}$

50 AHPM. Escribano Juan Manrique. Prot. 3361. Folio $648 \mathrm{r}^{\circ}$ y ss. Inventario de bienes del III duque de Pastrana, 1626. Publicado y estudiado por Dadson, T. J.: "Inventario de los cuadros y libros de Ruy Gómez de Silva, III Duque de Pastrana (1626)", Revista de Filología Española, tomo 67, fasc. 3-4, 1987, pp. 245-268.

51 AHPM. Escribano Juan Manrique. Prot. 3361. Folio 661 ro. Dadson, T. J.: Art. cit., pp. 250 y 253.

52 García López, A.: Art. cit., p. 173. Citamos del original: AHN. Nobleza (Toledo). Osuna. Leg. 3404, nº 3. Libro de mayordomía de Pastrana. Cuentas 1606-1626. Folio 779 ro.

53 García López, A.: Art. cit., p. 173, nota 84. Citamos del original: AHN. Nobleza (Toledo). Osuna. Leg. 3404, n 3. Libro de mayordomía de Pastrana. Cuentas 1606-1626. Folio 789 ro.

54 García López, A.: Art. cit., p. 173, nota 84.
} 
1605 el III duque de Pastrana había hecho una jornada a la localidad gaditana ${ }^{55}$. Los documentos de la mayordomía de Pastrana de todos estos años iniciales del siglo XVII son testigos, por las numerosas partidas que se refieren a ello, de las intensas relaciones que queremos poner de manifiesto ${ }^{56}$.

Si la obra de Cleves que citábamos llegó a Sanlúcar y entró en la colección del duque de Medina Sidonia es algo que no podemos concretar. De hecho, en el inventario de bienes que habían pertenecido a $\mathrm{D}$. Alonso, redactado tras su fallecimiento, no consta ningún cuadro con la representación de la Última Cena, ni "Cena" alguna ${ }^{57}$. Caben dos posibilidades, al menos. Que el cuadro no llegara a su destinatario, cosa extraña ya que en la documentación referida del ducado de Pastrana se afirma que el cuadro se envió. O que una vez en poder del duque de Medina Sidonia, éste lo vendiese. Al ser un presente de tipo familiar y, seguramente, con significado nupcial, esta opción podría descartarse. Optamos por pensar en alguna donación pía, probablemente a algún convento o santuario especialmente venerado por el duque de Medina Sidonia en la propia Sanlúcar o en otro lugar. El que más interesó al duque de Medina Sidonia que nos afecta fue el Santuario de Nuestra Señora de la Caridad de Sanlúcar, cuya iglesia se comenzó a construir en 1610. Ningún cuadro que represente la Santa Cena consta pertenecer o haber pertenecido a dicha casa ${ }^{58}$. Tampoco consta cuadro alguno que podamos identificar como el que tratamos aquí en los catálogos antiguos de la provincia de Cádiz 59 .

Años después, Francisco de Cleves realizó otro trabajo en Pastrana, esta vez para el concejo y ayuntamiento. Se trató de la obra "De pintar El arco de la castellana y doralle y dorar Las armas y açer dos escudos de las armas de mi señora la prinçessa", por lo que recibió del ayuntamiento 344 reales en 160960 . El dato procede de uno de los legajos del Archivo Histórico del Ayuntamiento de Pastrana, donde se recogen las obras del mencionado arco, situado antiguamente -hoy no se conserva- en la calle llamada de "la castellana", que recorre la villa de la parte baja a la alta cruzándose con la calle mayor, que es la que comunica el palacio ducal y la colegiata, a mitad de camino entre ambos edificios principales de la población. Los datos de las diferentes partidas sobre la construcción del arco señalan que fue realizado por el maestro albañil Francisco del Olmo y sus oficiales, y que el duque mandó que se le pagaran las demasías ocasionadas por ello, lo que indica que algo tuvo que ver, además del concejo municipal, en la iniciativa de su construcción. Otros pagos se refieren a empedrados en la puerta castellana, en la misma calle y en otras vías, junto a pagos por la cera "Para La Encamisada que se hiço al Rezivimiento de la Vuena Venida de los prínçipes mis señores", es decir, para una festividad organizada para recibimiento de los señores de la villa ${ }^{61}$. El arco decorado por Cleves era, por lo que podemos deducir, una especie de arco triunfal situado en el recorrido a seguir por los duques a su regreso a la localidad, levantado

\footnotetext{
55 Salazar y Castro, L.: Op. cit., pp. 579-580.

56 Alrededor de 1610 se recogen numerosos pagos por traída de ciertas pertenencias desde Sanlúcar hasta Pastrana, se celebraban honras fúnebres en la colegiata de la villa alcarreña por la duquesa de Medina Sidonia, etc. Cfr. AHN. Nobleza (Toledo). Osuna. Leg. 3404, nº. 3. Folios $890 \mathrm{r}^{\circ}, 908 \mathrm{v}^{\mathrm{o}}$ y otros.

57 Archivo Ducal de Medina Sidonia (Sanlúcar de Barrameda). Leg. 956. Inventario post mortem de D. Alonso Pérez de Guzmán y doña Ana de Silva, 14 de agosto de 1615.

58 Cruz Isidoro, F.: El Santuario de Ntra. Sra. de la Caridad, de Sanlúcar de Barrameda. Estudio histórico-artístico, Córdoba, 1997.

59 Romero de Torres, R.: Catálogo Monumental de España. Provincia de Cádiz (1908-1909), Madrid, 1934, 2 vols.

60 Archivo Histórico Municipal de Pastrana. Legajo 58/4. Sin foliar. Alude a este documento y a su contenido, sin citar concretamente la fuente -únicamente el archivo, el año y el carácter del documento-, García López, A.: Art. cit., p. 173. Véase también, del mismo autor, La estructura socio-económica morisca en la jurisdicción señorial. El ducado de Pastrana (1570-1610), Memoria de Licenciatura inédita, Universidad de Alcalá, 1993, p. 73.

61 Archivo Histórico Municipal de Pastrana. Legajo 58/4. Sin foliar.
} 
de obra permanente. La realización de esta construcción y el adecentamiento del piso de las calles indican el carácter ceremonial del recorrido acondicionado tanto como el carácter de la decoración que le dio Francisco de Cleves, a base de pintura, dorados y escudos de armas de la princesa, es decir, de la casa de Éboli-Pastrana. Cleves demuestra con ello, y con otras actividades relacionadas con su condición de pintor que veremos enseguida, haberse aclimatado perfectamente a su nuevo lugar de residencia. Parece que tenía tienda y taller abierto en la plaza Mayor de Pastrana, que le arrendaba el duque, y que se relacionaba profesional y comercialmente con sus vecinos y con habitantes de pueblos de la comarca62.

Francisco de Cleves falleció en 1611, tras sufrir una enfermedad y otorgar su testamento e, incluso, un codicilo. Ambos documentos han sido dados a conocer no hace mucho por Aurelio García ${ }^{63}$ y aportan una buena cantidad de datos sobre su vida y actividades en Pastrana y otros lugares. El testamento del pintor fue redactado ante el escribano público de Pastrana Andrés Escolar, el 6 de noviembre de 1611. En él Cleves se declara vecino de la villa alcarreña y natural de Amberes, en el "reino" de Brabante. Como tuvimos ocasión de ver -en nota-, es en este documento donde aporta el nombre de sus padres, que el escribano escribió como "anrrique de cleves y pasquala Sois". Encargaba ser enterrado en la iglesia colegial de Pastrana, en el lugar que determinasen sus albaceas testamentarios. Como es normal, también indicaba las misas que se debían decir por su alma, las ánimas del purgatorio y por sus padres, así como las mandas pías acostumbradas.

A continuación nos encontramos con un amplio repaso de deudas por cobrar y por pagar que nos ofrecen un buen panorama de su trabajo como pintor en Pastrana y sus alrededores, así como algunas noticias sobre su actividad en Guadalajara. Una primera partida se refiere a ciertas obras de pintura y otras cosas que estaban en poder de un vecino de la capital arriacense, el capitán Calderón. Se trataba de "un arca de noé que vale tresçientos Rs en ocho ducados", "una figura de un fevo con una muger Echada en una cama y su marco dorado que valdrá ocho ducados en diez y ocho $R^{S}$ " (Efebo, quizás Febo Apolo, con mujer echada en una cama), "un orffeo copia del Vassán en ocho Reales y Valdrá diez ducados" (un cuadro de Orfeo copiado de un original de Bassano), además de una "çerbatana" y ciertas "turquesas de plata", todo ello empeñado al capitán, por lo que Cleves pedía que se pagase y recuperasen. También tenía empeñado, esta vez en poder de un tal Diego del Arco, "Un lienço grande de dos baras de alto Poco más o menos" que representaba la Quinta Angustia. Estaba empeñado en 4 ducados, aunque Cleves lo valoraba en 8 , por lo que pedía que se pagase la cantidad por la que se había empeñado y se recuperase.

Después de aludir a deudas contraídas con diversos vecinos de Pastrana, se refiere a un trabajo por el que no se le había pagado más que una parte, por lo que solicitaba lo restante. Se trataba del "aderezo" de "Lo que estava en el techo por acavar", así como del pintado de las paredes, el dorado, los lienzos y el resto de la pintura (excepto el dorado del arco) de la capilla del Santo Cristo de la villa de Armuña, localidad situada a pocos kilómetros de Guadalajara. Debía cobrarse el débito al cura de dicha villa.

Otro cura, el de la villa alcarreña de Renera, le debía aún 3 ducados del precio (16 ducados en total) de un cuadro que le había pintado con la representación de una gitana, con su marco dorado. A una vecina de Albalate de Zorita, viuda llamada María Sánchez, le había pintado un San Juan grande (de dos varas de alto), y un San Francisco "que le pinté de nuevo" -quizás

${ }^{62}$ García López, A.: Art. cit., p. 171. Consta la compra de paño, por parte de Cleves, a un mercader de Pastrana en 1608.

63 Ibid. Transcrito, parcial y libremente, en pp. 175-177. Nuestra lectura es diversa en algunos aspectos, por lo que citamos el documento de su fuente: Archivo Histórico de Protocolos de Pastrana. Escribano Andrés Escolar. 1611. Folios $464 \mathrm{r}^{\circ}-467 \mathrm{v}^{\circ}$. 
aprovechando un soporte de pintura preexistente-. También le había reparado ("aderezado") una tabla de la Virgen y le había prestado "una gitana toda de Évano mía" que Cleves valoraba en 8 ducados. Por las obras realizadas le debía esa señora 80 reales, que debían cobrarse junto con "la gitana". Para otro vecino de Albalate, Lorenzo Serrano, había realizado dos cuadros con representaciones de su santo patrón: un San Lorenzo diácono y otro en el martirio. Solicitaba que se cobrasen los 10 reales que le debía por ellos, pues sólo le había pagado 30.

Cleves debía a un tal Felipe de Velasco cierta cantidad por deudas del juego de los trucos, además de haberle dado empeñadas "dos tablicas de adonis y benus y de apocaris y céfaro en cien $R^{e S "}$ " También había empeñado a un pastelero llamado Martínez "una Echura de un xpo en doçe $R^{e s}$ y Seis quartos", a "la Melchora" "una Hechura de un niño Jhs con una estrella de los pasos de la pasión en doçe $R^{e s " ~ y ~ a ~ u n ~ t a l ~ F r a n c i s c o ~ H e r n a ́ n d e z ~ d e ~ B e t e t a ~ " u n ~ a g n u s ~ d e y ~ d e ~ c r i s t a l ~ g u a r-~}$ necido con oro en $V^{t e}$ e un $R^{e S " . ~ U n ~ h i j o ~ d e ~ e s t e ~ u ́ l t i m o, ~ l l a m a d o ~ F r a n c i s c o ~ H e r n a ́ n d e z ~ d e ~ B e t e t a ~}$ el mozo, tenía en su poder un cuadro de una "gitanica" casi acabada, por la que ya había adelantado a Cleves 2 ducados a cuenta. Otro tanto había adelantado a nuestro pintor un D. Cristóbal de Guzmán por otra gitanilla que casi había terminado de pintar. Había empezado a pintar para un sombrerero llamado Miguel un San Jerónimo; el sombrerero le había adelantado un sombrero y 4 reales.

Francisco de Cleves tenía en su poder por entonces un lienzo con la representación del "Rico avariento" que pertenecía a la iglesia de la localidad de Horche, y del que estaba realizando una copia. El pintor flamenco confesaba también que el santero de Valdeconcha ("de nra $S^{a}$ de las Candelas"), otra localidad de la comarca, le había dado 35 reales a cuenta por la ejecución de un lienzo de Santa Ana y la Virgen que había terminado recientemente. También tenía en su poder otro lienzo de San Lorenzo, esta vez propiedad de un racionero de la colegial de San Francisco de Pastrana apellidado Trillo; dejaba el encargo de que se le devolviese. Quizás lo tenía para realizar una copia, quizás una restauración. Entre tantas obras que Cleves tenía en su casa pertenecientes a otras personas, encontramos una "una ymagençita de nra $S^{a}$ del pópulo", que era de "del conventual", y que también se debía devolver a su propietario.

Francisco de Cleves indica en su testamento otros muchos detalles sobre su actividad en la zona de Pastrana. Sabemos que un labrador de la villa de Escopete llamado Pedro Fernández le había encomendado el dorado de unas andas procesionales, trabajo por el que aún le debía cinco reales. Una vez pagada la citada cantidad, se le devolvería un Niño Jesús de bulto, entregado probablemente como fianza, o quién sabe si para ser pintado o dorado.

Entre las posesiones que Cleves declaraba tener en su casa se indica la existencia de 295 estampas, de procedencia y temática desconocida; un San Juan Evangelista pequeño de pintura; un pequeño crucifijo; dos lienzos que hacían pareja de Cristo y la Virgen; otro de la degollación de San Juan con marco dorado; "un niño Jhs sentado en una almohada"; una imagen de la Quinta Angustia; un San Francisco grande; un Niño Jesús; dos "alones"; un Orfeo; una cena "de claro y negro", es decir, en grisalla; un lienzo de una gitana; otro de la Magdalena; dos cuadritos, uno de la "Humanidad" de Cristo y otro del Espíritu Santo.

Después de hacer alusión a ciertas deudas con vecinos de Albalate de Zorita -entre ellos un escribano-, se refiere a sus deudas con un tendero de Pastrana y que, para saldarlas, le había comenzado a pintar dos cuadros -que aún no había concluido- con representaciones de Santa Ana y de la Concepción, respectivamente. Debía a un tal Francisco de Horche "diez y ocho panes" (quizás de oro), a cuenta de un Niño Jesús que se había comprometido a hacerle.

En el testamento Cleves también se refiere a su época de pintor al servicio de D. Rodrigo de Mendoza, D. Enrique de Mendoza y del V duque del Infantado. Concretamente alude a ciertos memoriales -que desconocemos- en los que podía encontrarse información sobre las pinturas que había realizado para estos señores. También se refiere a varias obras que había realizado para el duque de Pastrana. Se refiere a un cuadro de la Cena, quizás el ejecutado para el duque en 1607. Luego, a una serie de seis lienzos que representaban a "los padres del yermo", 
a otro de la Trinidad "del çielo y de la tierra" y a otro del Niño Jesús "que mandó Su exa. Lo llevase a md. [Madrid] Juan de almd. Su maestresala". Esta última referencia parece aludir al traslado del último de los cuadros únicamente. Cleves los valoraba en 300 reales, una parte de los cuales aún se debía satisfacer64. Al menos cuatro de los referidos a los "padres del yermo" deben ser los que se registraron en el inventario antes visto de 1626. Ninguno de los otros consta en ese registro 65

Por último, nombraba como albaceas testamentarios al reverendo Alonso de Trillo (seguramente el racionero antes mencionado) y a Esteban Bayo, vecinos de Pastrana. Dejaba por su única heredera a su hija, Catalina de Cleves.

Poco después otorgó un codicilo al testamento, ante el mismo escribano, como vimos. El documento tiene fecha del 12 de noviembre de 1611 e indica que se redactó con motivo del pago que se debía por otra obra pictórica. Se trataba de un cuadro de la Adoración de los Reyes que Cleves había pintado para el doctor Fortea (presidente del Consejo del duque, como veíamos), ya difunto, que tenía en su poder su testamentario, el canónigo de Pastrana Gaspar Hurtado. La obra valía alrededor de 500 reales y no se había pagado por ella más que una parte, por lo que el pintor flamenco solicitaba el resto, a obtener de los bienes del fallecido doctor 66 .

El testamento (con su codicilo) nos proporciona mucha y muy valiosa información sobre la vida y obra de Cleves, especialmente en el período de su vida en el que residió en Pastrana, aunque, como hemos visto, sin dejar de aportar noticias de notable interés sobre otras etapas. Ya hemos visto lo relativo a su origen familiar. Nos sorprende que también trabajase para D. Enrique de Mendoza -que quizás sea el hermano del V duque del Infantado, muerto en $1595^{67}$, aunque ignoramos cuándo y en qué condiciones. Es muy interesante la referencia a un cierto número de obras realizadas para el duque de Pastrana (y que aún estaban por pagar), lo que confirma el hecho de que Cleves hubiese ejercido como pintor de corte para él. La referencia a su hija, Catalina de Cleves, nos indica posiblemente que fue hombre casado, aunque la ausencia de referencias a su esposa en el testamento nos suscita algunas dudas al respecto ${ }^{68}$.

Pero lo más interesante del testamento es, quizás, el gran cúmulo de referencias a trabajos de todo tipo que llevó a cabo para los habitantes de la Alcarria en torno a Pastrana. Demuestra con ello un sentido comercial nada extraño para su origen flamenco, y una rara habilidad para hacerse con todo tipo de trabajos. No abundan los más habituales en los pintores de la época y zona, que tuviesen cierto prestigio, como retablos u obras mayores realizadas para iglesias o cofradías, aunque el dorado de andas y la -ocasional- decoración de ermitas y capillas puede encuadrarse en ese ámbito laboral. Sí que creó en torno a su taller algo que podemos considerar como un auténtico mercado de encargos de particulares, bien por pura relación cliente-artífice, bien como medio de pago de sus diferentes deudas. Cleves pintaba cuadros de devoción del tipo más habitual y hacía copias o restauraba obras, pero también pintaba lienzos del tema tan flamenco como es el

\footnotetext{
64 Aurelio García López (art. cit., p. 174) se refiere a este dato, pero indicando que los lienzos que nosotros leemos como de los "padres del yermo" (ermitaños o del desierto) eran de "Los Padres de la Iglesia". Este autor supone que estas obras y los otros dos lienzos podrían formar conjuntamente un retablo, sin fundamento alguno. Tampoco tiene fundamento documental -ni de otra índole- la afirmación que hace referida a que estas pinturas las "realizó para un regalo de su señor al [duque] de Medina Sidonia".

65 Un cuadro de una gitana con un niño en los brazos que allí consta $\left(f^{\circ} 661 \mathrm{v}^{\circ}\right)$, puede relacionarse con Cleves, por razones de índole iconográfica.

66 El documento fue dado a conocer y publicado parcialmente por García López, A.: Art. cit., p. 174.

${ }^{67}$ Enrique de Mendoza y Aragón. Hermano del V duque del Infantado. Caballero de Santiago. Arteaga y Falguera, C. de.: Op. cit., tomo I, p. 355.

68 Dudas que también manifiesta Aurelio García López (art. cit., p. 171), a las que se suman las de que tuviera descendencia, pese a lo que acabamos de ver: "en su testamento [...] no hace ninguna referencia a tener hijos".
} 
de género -sobre todo "gitanas"- para todo tipo de clientela, incluida la eclesiástica, y otros, tan comunes en su producción como extraños a la habitual de los pintores españoles del momento, como son los mitológicos.

Francisco de Cleves falleció en Pastrana el 16 de noviembre de 1611. Como pedía en su testamento, fue sepultado en la iglesia colegial de San Francisco, junto al púlpito del lado de la Epístola ${ }^{69}$.

69 Art. cit., p. 171, nota 75. 